RUNNING HEAD: High-conflict parents in mediation: an analysis....

\title{
High-conflict parents in mediation: an analysis of dialogues and sources of conflict
}

A significant proportion of parents in mediation present destructive and escalating conflicts. In a naturalistic study of sessions with high conflict couples, we observed dialogues with frequent interruptions, rapidly shifting subjects, and emotional attacks. A systematic search revealed eight distinct sources of conflict that interfered with the mediation process: Two related to the breakup, four regarding differing concerns of care for the child and two mainly about the contextual conditions for childcare arrangements. The article describes these sources of conflicts in a format that could increase the capacity of mediators to recognize and address them during the process of mediation.

It is an established finding that children from divorced families experience more individual and social problems than children from intact families (Emery 1999; Kelly 2000). In addition to the reduced economic status after the divorce, the main explanation of these issues has been found in separating parents with higher conflict levels (Amato 2000; 2001; Cheng et al. 2006; McIntosh, Wells, and Long 2007). Although having a relationship with both parents is considered a resource for the child, these relationships can lose value or even turn into a burden if the parents' conflict affects their caring abilities.

Norway is not alone in witnessing a steady increase in the number of marriages and cohabitations ending in divorce or separation. This increase, combined with the increased awareness of the harmful effects of parental conflict on children, was central in the 1990s when the Norwegian government passed a law mandating mediation for all separating parents with children 16 years of age and younger. The main intention was to help parents come to an agreement and cooperation regarding future care for the children (The Law on Marriage 1991; the Law on Children and Parents, 1981). Couples who bring their case to the court must have attended mediation first. Only one session is mandatory, but the process is free of charge for up to seven sessions. The sessions are led by educated mediators, including psychologists, 
RUNNING HEAD: High-conflict parents in mediation: an analysis....

social workers, and a few lawyers. The sessions take place at family counseling care centers or at other locations led by external mediators.

There have been two recent evaluations of the Norwegian mandatory mediation arrangement including the FORM-project at the Department of Psychology, University of Oslo (Gulbrandsen, and Tjersland $2011 \mathrm{a}, \mathrm{b}$ ) and a study by The Norwegian Centre for Applied Research, Technology and Innovation, SINTEF (Ådanes, Haugen, Jensberg, Lossius Husum, and Rantalaiho 2011). This study was based on the FORM-project, which followed 154 couples throughout the mediation process with questionnaires and audio recordings from the sessions, as well as follow-up after the mediation. Most of the couples (116 couples) arrived with low to moderate levels of conflict (LCL/MCL groups), and 80.2 percent reached an agreement after one or two sessions. Eighteen months later, nearly 90 percent had reached an agreement. The vast majority of the parents in both studies reached an agreement and was satisfied with the process and the outcome. This finding is in line with the findings of international studies (Baitar, Buysse, Brondeel, de Mol, and Roper 2012; Shaw 2010), although only a few studies have focused on mandatory mediation.

However, there is a significant proportion of couples in mandatory mediation that present with major disagreements regarding how to arrange childcare in their lives as separated parents. Therefore, we were particularly interested in what happens to couples who had contradictory ideas about the future and thus experienced a high level of conflict. 38 cases were identified as "high-conflict couples" (HCL couples) based on information provided by the parents before mediation and from the mediators after the first session. For this subgroup, the effects of mediation were rather limited; 71.1 percent of the HCL couples did not reach an agreement that satisfied both parties. For the majority of couples, the conflicts continued, and after 18 months, 53.7 percent still had not reached an agreement. Out of the seven available 
RUNNING HEAD: High-conflict parents in mediation: an analysis....

sessions, a disconcerting number of HCL couples only made use of the one mandatory session (Tjersland, Gulbrandsen, and Haavind 2015).

Based on these results, we took a further step and looked into the dialogues in the mediation sessions of parents experiencing high levels of conflict to see how contentious arguments actually played out and how the two parties responded to the mediation. The aim of this study was to identify the characteristics of the conflict dynamics that would hamper the dialogue and reduce one or both parties' capacity to see the needs of their children and contribute to feasible solutions.

\section{Understanding the driving elements of conflict between parents in mediation}

A definition of conflict by Ekeland (2004) identifies patterns that are often to be observed in the dialogues between separating parents:

"We talk about conflict when differences between mutually interdependent persons are experienced as excluding or threatening to the individual's needs and interests, and tensions and emotional reactions occur due to one of the individual's experience of the other person as using power to influence the situation to his or her advantage" (Ekeland 2004, p. 88, our translation).

The definition highlights two characteristics of conflict. First, a mutual dependence must exist (such as when the couple has children together). Second, the ideas about how to handle the topics in question must appear incompatible and impossible to accept, thus creating high levels of tension between those involved. Ekeland further notes a third characteristic often 
RUNNING HEAD: High-conflict parents in mediation: an analysis....

found when distinguishing between the conflict itself and how it affects the persons involved: conflicts tend to escalate with time and have a life of their own, making those involved to feel as unwilling victims of what is going on.

The literature on mediation mention different ways to understand and intervene in parental conflict. Early studies focused on solving disagreements around specific issues such as childcare, living situations and economic issues (Coogler 1978; Haynes 1981). Later, several mediators, inspired by ideas from psychology and family therapy, emphasized the importance of taking into account the emotional and relational processes underlying the differences in views. A variety of terms have been used regarding the psychological aspects of the conflict that a professional should be aware of and address, such as "ways of reacting that hinder the mediation process", "make space to express emotions", "validating emotional reactions", "recognizing and strengthening self-esteem", "changing attitudes", "articulating a dialogue about the history of the conflict", "building trust" and "changing the interaction from being characterized by use of power to openness and respect" (Brown 1997; Bush and Folger 2005; Irving and Benjamin 2002; Lang and Taylor 2000; Saposnek 1998; Sbarra and Emery 2006; Windslade and Monk 2001).

There have been several attempts to categorize different levels of conflict between partners (Weingarten and Leas 1987 (5 levels); Weeks and Treat 2001 (3 levels)), different types of conflict between couples (Gottman 1993, 1994: "violent couples" and "hostile couples") and different personalities (Eddy 2016). However, there are reasons to question how helpful such categorizations are for the mediators.

The literature on mediation uses fairly broad and generic terms when describing conflict levels, a couple's characteristics or emotional issues within a relationship. One explanation of this is that most studies are based on retrospective reports of data from questionnaires or 
RUNNING HEAD: High-conflict parents in mediation: an analysis....

interviews with mediators and clients. There has been a distance between the interaction that takes place in mediation and the verbal reports about it. However, there are exceptions to the generalized descriptions. In a recent study, experienced mediators provided very explicit descriptions about common challenges in mediation and shared many converging ideas about how to address them (Poitras and Raines 2013). Phenomenological descriptions of emotional reactions during mediation have also been provided by data from reflexive journaling and group discussions (Picard and Siltanen 2013).

To better understand the driving elements of conflict between parents in mediation, researchers have emphasized the need for more observational studies of the natural mediation processes (Emery, Sbarra, and Grover 2005; Saposnek 2004; Wall and Dunne 2012). There have been very few studies of this kind (Garcia 2012; Heisterkamp 2006; Jacobs 2002; Kressel, Frontera Rutgues, Forlenza, Butler, and Fish 1994; Olekalns, Brett, and Donohue 2010; Tjersland 1999), and most have been limited to single case studies.

\section{Methods}

\section{$\underline{\text { Design and procedures }}$}

154 couples with children were recruited from four family care units and one external mediation unit over a period of seven months. The positive response rate was 75 percent. The couples arrived from diverse catchment areas and thus represented different demographic groups in Norway including urban and rural areas. Most of the parents (77 percent) were still in the separation process, but many of them were already living apart. The rest of the parents had been separated for up to several years. The parents met for a second round of mandatory 
RUNNING HEAD: High-conflict parents in mediation: an analysis....

mediation because they considered bringing the case to court. Twelve mediators, most of whom had substantial experience with mediation, led the process and collected data. This was a naturalistic study of the usual mediation practice at the family care units within the general frames of the law to assist parents in the process of making plans for the arrangement of care for their children in the future.

Prior to the first session, each parent answered a questionnaire about their background, how similar they perceived their views were to those of their partner, their expectations for mediation and how confident they were in finding a solution. After each session, they anonymously answered a short evaluation questionnaire. The mediator wrote a short memo commenting on potential challenges for the mediation process and the outcome when the mediation was over. Every session was audio recorded. After 18 months, follow-up telephone interviews were conducted with each parent to assess their perception of the mediation, the level of cooperation between the parents and information about their break up.

\section{$\underline{\text { Sample }}$}

As previously mentioned, 38 couples with a high level of conflict (HCL) were identified. This categorization was based on the following two sources: the compatibility of views as presented by the parents upon first arrival and the mediator's assessment of the conflict level after the first session. The demographic characteristics of the HCL group resembled the remaining 116 couples. There were two main aspects of conflict with considerable differences: The hope of finding a solution was rather low in the HCL group compared to the remaining couples (a mean of 2 compared to 6 on a scale from $0-7$ ). Furthermore, the majority of HCL couples met for mediation as a necessary step towards taking their conflict to court (58 percent compared to 11 percent).

As for the mediation processes, there were both differences and similarities among the 38 
RUNNING HEAD: High-conflict parents in mediation: an analysis....

couples in how the conflict dynamics unfolded. The 38 cases represented a broad and complex set of issues and dynamics often found in mediation practice that lead to a dead end.

\section{$\underline{\text { Analysis }}$}

The analysis was inspired by a social constructionist take on grounded theory (Charmaz, 2008). On the one hand, we focused on the empirical materials (transcribed audio recordings) and studied the dialogue between the parents in conflict. On the other hand, we interpreted their statements in a relational and interactional context. A statement at a given point in the dialogue was always interpreted in light of what had been previously said, not said or hinted at concerning both their shared history and knowledge about the others' viewpoints and reactions. Thus, the analysis was both descriptive and interpretative.

Additionally, we drew on years of experience working with couples and parents in conflict and our knowledge on mediation theory and research (Tjersland and Gulbrandsen 2010). This approach allowed us to take an external, observational perspective on the relationship between the parents and understand the perspective from each parent's separate point of view.

The analytic process can be described as a hermeneutic spiral, turning at least five times around the axis of "conflict-oriented dialogues". The first turn consisted of a comparative analysis of the dialogues of two couples from the LCL group to two couples from the HCL group. After listening to, transcribing and writing a memo from each couple's first session, some differences emerged in how the parents addressed each other and how they described and spoke about their children. These differences were used as a starting point for the exploration of similar elements of the interaction in other HCL cases, resulting in a description of characteristic dialogical patterns in the HCL cases. 
RUNNING HEAD: High-conflict parents in mediation: an analysis....

The second turn consisted of listening to and transcribing all four mediation sessions for the HCL cases with different mediators. The number of sessions varied from one to several. Again, a memo was created after transcribing each session with a focus on three key questions. First, what topics did the discussions revolve around? Second, how did the parents relate to each other? Third, how did they relate to the guiding interventions from the mediator?

The third turn can be described as a new round of analysis, starting with seven more cases transcribed and analyzed according to the second turn and creating a matrix based on $13 \mathrm{HCL}$ cases. The matrix was made up of the following categories: topics being addressed, descriptions of specific situations, chains of arguments used by parents and ways of responding to these arguments.

The fourth turn resembled what Charmaz (2008) describes as the development of analytical categories. Comparing notes on the cases, we found topics that were repeatedly addressed by the parents as follows: the proportion of time with children, how and with whom the children lived, what to tell the children about the present situation, and how to handle their relationship with new partners. In discussing opposing solutions, both parties usually referred to the same premise of "what is best for the child". Some fathers also argued on the basis of fairness. However, as the dialogues became more heated and emotional, some patterns emerged that suggested different sources of conflict. Behind the intense discussions about details of how, when and whom, we started to identify and sort out different dynamics of conflict. Some cases were dominated by one source of conflict, whereas several sources influenced others. In this way, eight sources of conflicts were identified.

The fifth turn of analysis included reading through the texts from 15 additional cases to test the validity of our descriptive and analytic categories for the sources of conflict. This analysis 
RUNNING HEAD: High-conflict parents in mediation: an analysis....

resulted in the addition of two new categories. Finally, we listened to the last ten cases, most of which consisted of one session without the support for additional categories.

In the fourth and fifth turns of the analysis, the first and third authors read the dialogues independent of each other before sharing what they found as the driving elements of conflict in each case. Differences were discussed both between them and with the second author before reaching a consensus.

\section{Results}

\section{Characteristic dialogical patterns in the HCL cases}

Frequent shifts of topic and a high level of emotional tension characterized the dialogues among HCL parents in mediation. For instance, as one parent addressed an issue about the visitation schedule, the other would reply by bringing up issues related to the breakup, which led the first to discuss a third topic. Briefly described, the following patterns were present in the dialogues:

- Chaos: frequent interruptions, change of topics and escalations of emotions

- A fundamental lack of trust: one or both parents were in a constant state of alertness to the potential hidden motives of the other

- Communication characterized by attack and defense

Compared to the dialogues between couples with a low level of conflict, these aspects were absent or seldom found in the interaction of the HCL group:

- A recognition of the contribution of the other parent

- Co-constructive descriptions and narratives about the child 
RUNNING HEAD: High-conflict parents in mediation: an analysis....

- Taking the perspective of the child without using it as an argument for a specific solution favored by one parent

- Openness and attentiveness with regard to the other parents' emotional reaction.

- A search for viable solutions

Faced with these destructive patterns, the mediators were constantly challenged in their attempts to direct the dialogues in a more constructive direction.

\section{$\underline{\text { Eight sources of conflict }}$}

By attentive listening and reflection over the frequent shifts in topics and the high emotional tension in each case, we were able to disentangle eight sources of conflicts. Two of them were connected to the breakup, four of them were related to incompatible ways of seeing and relating to the child and two were mainly about the contextual conditions for how childcare could be arranged.

\section{One refuses to accept the breakup while the other refuses to talk about the topic}

Even though the questions regarding the children were in the foreground, reactions of hurt, sorrow and despair evolving from one of the parents invited a dialogue about a different topic, the potential for reconciliation. The response from the other partner was mainly to ignore these invitations, staying on the topic of practical arrangements and reminding the other of this focus. Sometimes the rejecting partner was drawn into this topic and defended the break up by detailing how difficult the other had been to live with. The conversation then returned to the question about time spent with the children. The despair and grief of the inviting part 
RUNNING HEAD: High-conflict parents in mediation: an analysis....

was sometimes expressed as threats, "If you want to leave, that is fine, but the children are staying with me!"

In one couple, the woman became pregnant while they were living together, but she moved out three months into the pregnancy. They now lived a great distance apart, and he asked for mediation when their child was one month old. In the session, he addressed several topics at once:

Father: And then the little one came, and we were going to move in together again. We talked about this repeatedly. "We're coming to you soon", you would say, but you never did. And yesterday nobody called me. We had agreed that I would have her yesterday. Why didn't you call me? Because you told me, in your own words, that you hadn't told your parents that she was going to be with me. And that's why she wasn't... What I care about now is agreeing on an arrangement for care for the child. Be friends and cooperate. My lawyer is paying attention, and he is looking for the best option for me in this!

The father oscillated between asking for reconciliation, wanting care arrangements for the child, accusing the mother's parents and threatening the partner with court involvement by mentioning his lawyer. The partner was silent, avoidant and unclear. It was difficult to determine the possible reasons for these reactions, such as ambivalence about reconciliation or fear or doubts regarding care arrangement. The mediator struggled to find a constructive focus.

2. One partner has strong grievances regarding how the breakup occurred while the other is avoiding the topic 
RUNNING HEAD: High-conflict parents in mediation: an analysis....

The dialogues in these cases were mainly about experiences of betrayal and humiliation in relation to the break up. Typically, one or both had shared secrets that used to be intimate and theirs alone with friends and family or one partner found out about something the other had been hiding. Infidelity was a particularly sensitive topic. The conflict was not so much about the fact that they had broken up as it was about the way in which it had occurred. Attempts to address the topic of care arrangements for the child failed miserably.

One example comes from a couple that had shared many years together and had tried couple's therapy. She knew that he had a new partner but found it almost degrading to have to speak of it. She expected him to provide this information.

Mother: I would like to point out that he was the one who broke up with me. In fact, Ifeel like that has to be said before we start any process of mediation: I've lost all my trust in him! I cannot go any further in this process if he is not willing to play with an open hand. I am going through a tough struggle now. What has happened has to do with his private life [in] the last two years and the last weeks. Now he even refuses to recognize it. It has to do with something as fundamental as identity. And this is important for me to sort out because it has to do with what we tell our kids. I should also mention that I've received quite a few comments from my children and our friends. It is about our private separation and about his plans for living. And he hasn't let me in on this! This happens without him actually talking to me about it! This means he is taking shortcuts. He is being disloyal to me. The trust we had is totally broken. It is important for me to make this explicit.

Her speech rapidly oscillated between tears and rage. He remained silent, diverting his gaze. When he finally spoke, he asked her to stay on the topic of childcare arrangements, emphasizing that this was not the time for her proposed topic. She exploded. 
RUNNING HEAD: High-conflict parents in mediation: an analysis....

There are incredible forces at play here. This woman expressed intense vulnerability after being rejected by the man she once chose as a partner for life. To her, it was a fundamental threat to her very identity and self-esteem. She expressed a need to understand and reconcile with the other person's choice, and she asked for help in this process. His avoidance can be understood in different ways. It could be an expression of shame connected to his actions, of helplessness and lack of clear answers for his former partner, or of fear that validating her struggle might reawaken her hopes for reconciliation.

In both of the above illustrations, one parent addressed topics that were formally out of place. The formal aim for the mediation is to discuss and find a solution for childcare arrangements, and topics of betrayal and grievances are out of place. This poses a great challenge for the mediator because ignoring these pleas from one parent is likely to incapacitate any dialogue about childcare arrangements. On the other hand, making space for such topics may break the alliance with the other parent who wishes to focus on the care for the child, which is supported by the laws on mandatory mediation.

3. One parent is concerned about the other's care for the children, but the other rejects the $\underline{\text { topic }}$

In some cases, one parent expressed concerns about the other's problems, describing them as a serious threat to his or her ability to care for the children. These were issues such as drug abuse, gambling addiction, anger management, mental health problems, an unstable life situation or frequent change of partners. When the accused partner rejected these claims, the accuser would bring up more examples, which was met by counterattacks. The worried partner often ended the dialogue in a tone of hopelessness, "You'll never change!", or in desperation and appeal, "You have to get a grip on your life!" 
RUNNING HEAD: High-conflict parents in mediation: an analysis....

Such concerns were frequently triggered by one specific episode, leading to abrupt changes in childcare arrangements and new conflicts reinforcing the existing dynamics. The parents refused to validate each other's experience. One example is a couple that had collaborated well for years over the care arrangements for their ten-year-old son, having predictable arrangements and celebrating Christmas together. Upon coming to mediation, they had been in chronic conflict for roughly a year due to an incident of the father driving his son while intoxicated. Child welfare services had called the mother to alert her of this incident in the middle of the night, asking her to come and pick up the son.

Mother: This is really frustrating to me, and it makes me concerned and angry. So I tell his dad that there is no way he'll get to celebrate Christmas with us this year. But when Jacob found out, he felt very sad about it. So I call his dad a bit later to invite him anyway. But then Dad didn't want to come. What's more, he even said that there was no way he would take Jacob every other weekend anymore!

Father: She refuses to let me to see my son. She even uses Jacob's phone to do so (raises his voice). Ole (mother's new partner) has no right to use Jacob's phone to tell me off. The first time he did so he did it in front of my son, on my son's phone, while he was listening!

Mother: But do you know why he did? If you want to avoid that, perhaps you should not come around to beat me up while your son watches.

The concern for the son released counterattacks, expanding the areas of concern from alcohol use to new partners and violence. In other cases, it started with concerns about gambling habits or abuse of medicines and expanded to others such as how one parent continually brought new lovers into the life of the child.

These examples illustrate a typical situation, in which the topic is legitimately within the scope of the mediation, namely, the care arrangements for the child. However, the way the 
RUNNING HEAD: High-conflict parents in mediation: an analysis....

concerns around the topic are dealt with ends the dialogue. This poses a challenge for the mediator; on one hand, having an ethical responsibility for the child's wellbeing, the mediator will inevitably consider how much truth there is in these accusations and what the real care situation is similar to with one or both of the parents. On the other hand, delving into this may be considered allying with one of the parents and thus breaking the dual alliance necessary for the mediation.

\section{One parent is concerned about the other's presence and empathizes with the child's} $\underline{\text { reactions but is rejected as overly sensitive }}$

The main concern was not the other parent's problems in life, but that he or she did not see, understand or react when the child showed signs of distress. The parents interpreted the child's behaviors differently, especially with younger children. The accused parent would often reply by accusing the other of conflating his or her own reactions with the child's and projecting reactions onto the child.

Mother: She became three years old this Christmas, and I don't think she is old enough to travel so often between us; I see that now. She needs one home. I can tell by the way that she reacts; she needs to spend less time at her dad's now until she is a bit older. I think it is important for her to have one steady base and not split her time between two homes like that. She seems a bit confused sometimes, in my opinion, as to what is true here and what holds there. She's not able to differentiate completely. I also notice that she seeks much more contact with me when she has been away from me and from her home for a while. It might be that she's the same when she's with you, but she seems a bit torn. She is uneasy at night in the beginning. She comes into my bed after being tucked in. Last night, she even wanted to sleep 
RUNNING HEAD: High-conflict parents in mediation: an analysis....

on my stomach, that is, as close as possible. I feel almost as if she really needs to come back, in a way. That's the main reason why I've requested mediation.

Father: Because this is what you've felt the whole way, right?

Mother: Yes. I have, or, yes, that's correct. It has been my opinion that she needed to have one home since the beginning.

Father: I find that incredibly sad...To me, I have a good feeling about this. But you project your own needs, wishes, longings and loneliness onto the child. I know it provokes you to hear this, but it is how I experience it. What I just heard is based on the mother's needs more than on what is best for the child...I am a reliable and a good father for the child.

For several of the couples, this was their second round of mediation. The parents had reached an initial agreement regarding care for the child immediately after the breakup. However, the desire to reach an agreement or guilt over initiating the breakup had driven one parent to compromise too much. Upon witnessing distressed reactions from the child because of the current care arrangements, he or she regretted this. After putting the separation behind and gaining more control over his or her own reactions, the parent initiated negotiations to change the care arrangements.

As mentioned above, general considerations or principles regarding "what's best for the child", inspired by developmental psychology, were typically used in the arguments.

However, the issue of the child often got lost in the arguments. Expressing one's own needs to see the child seemed to be illegitimate for the parents to bring into the discussion. The parent who felt under attack would claim his or her right and importance as a parent and dismiss the other's concerns. The discussion often revolved around concrete time schedules for care arrangements, leading them to a somewhat deadlocked position. Both parents would become rigid, and the mediation would lead to nowhere. The mediator had the fruitless role of 
RUNNING HEAD: High-conflict parents in mediation: an analysis....

validating various general principles such as "a child needs one home " and "a child needs a father".

$\underline{\text { 5. Economic issues are a concern, but one or both parents treat this as an illegitimate topic of }}$ $\underline{\text { discussion }}$

Even though economic concerns were present, they were often not addressed directly, at least not at the start of the mediation. It was as if this concern was undignified to verbalize. Instead, the parents discussed the child's need for stability, for seeing both parents and so on. The concern for economic issues was present as an underlying touchy subject, such as fear of managing the expenses and working full time while caring for the child. In Norway, the amount of child support and taxes are closely related to visitation time and the registered home address for the child. Some of these couples consisted of mothers staying at home and employed fathers. Others had mothers working full time and fathers that were unemployed. There were also cases where both parents had bought new homes and were in deep debt. It appeared as though this topic was somehow dangerous to talk about, as if something could be uncovered.

In one such case of a couple with two sons, a 12- and a 15-year-old, the younger son had a registered home address at the mother's place while the elder shared an address with his father. For several years, the sons had stayed together with each parent half of the time. The solution had given both parents tax advantages. Lately, the older son started to spend less time with his dad. The mother had observed conflict between the father, his new cohabiting partner and the two sons. She initiated another round of mediation to change the agreement to "reflect the realities". The father seemed to agree with the idea to change the agreement to allow the eldest son to spend more time at his mother's, but when it came to the question of formally 
RUNNING HEAD: High-conflict parents in mediation: an analysis....

changing his home address, the conversation turned away to other topics. The mother brought up the conflicts with the father's new partner. The father defended himself and attacked her for being disloyal. The dialogue became heated and the parents ended up arguing as enemies. As they left, the father hinted at the tax benefits to the mother for changing the older son's address, but the session was over. The topic was left undiscussed and unexplored, and they did not return.

In cases like this, the responsibility of economically providing for the child may be excluded as an illegitimate topic in mediation.

\section{The child initiates changes, but it is interpreted differently}

As in the case above, the child could have initiated a change in living pattern, causing the parents to ask for mediation. This often occurred when the children lived with one care arrangement for a while, but upon reaching their early teenage years, changed habits. This escalated the conflict between the parents, causing disagreements on how to interpret and meet this behavior. In some cases, one parent encouraged listening to the child, while the other held that "as parents, we have to tolerate making unpopular decisions". In other cases, one parent accused the other of contributing to the child's initiative, "You make her dislike being with me!" The blamed one would defend him- or herself by replying, "On the contrary, I encourage her to go!"

One example is a case where a 14-year-old girl was living with her mother but stayed with her father every other week. This arrangement had worked well for many years and involved some financial benefit for the mother, as the daughter had her home address registered at the mother's place. The father called for mediation upon receiving a phone call from his daughter one evening. She had a fight with her mother and "did not want to live there anymore", and 
RUNNING HEAD: High-conflict parents in mediation: an analysis....

asked her father to pick her up. The mother explained this as a natural event in the motherdaughter relationship in a phase of change, while the father accused her of not taking their daughter's wishes seriously. He emphasized the daughter's age and her right to take part in such decisions and held that he would take the matter to court to ensure that right. The mother replied with financial concerns. If the daughter moved, she would not be able to keep her apartment! This couple's previous agreements regarding economic matters had been quite smooth. Both had a solid economic status, and the strong reactions observed in this session may not have been so much about the money as it was about the daughter's wish to leave her mother.

These parents struggled with several sources of conflict. This was often the case in situations where children had initiated change. In addition to concerns such as money and the child's well-being, there is the potential conflict of how one understands and handles the child's initiative and reactions. This can pose a challenge for all parents, whether they are separated or not, especially when the children reach their teenage years. In the wake of a divorce, the process of interpreting the child and sorting out what to focus on and what to place significance on can be extremely challenging, as it may be tainted by or conflated with the conflict between the parents. The mediator can play a central role in helping the parents differentiate and sort out the different sources of conflict in such situations. There is also the possibility to invite the child into the process for one session or more, not for deciding on the disputed question, but to give the parents richer insight into the child's perspective before making decisions.

\section{Different life projects - threatening the feasibility of shared care arrangements}


RUNNING HEAD: High-conflict parents in mediation: an analysis....

Often parents must make decisions about their life after a break-up that make shared care arrangements and contact with the children difficult. Among the couples in our study, this involved a parent considering moving because of a new job or partner, to start an education or to return to his or her roots and family. These geographical changes posed challenges to the steady contact between the children and both parents. A new partner in one of the parent's life, and thus in the children's life, could also be perceived as a threat to the other parent's contact with the children and sense of control over their lives.

In one case, the children lived at the mother's place, and the father saw them every other weekend and one evening a week. They had been divorced for three years, and the father was deeply involved in his children's lives. The mother now wanted to move to a different part of the country to live with her new partner and for career opportunities.

Father: My ex-partner has told me she wants to move far away to a place that leaves me with very little time at all with my kids. It is not possible for me to move as well, so this, in my opinion, is not an option. She wants to take the kids to a place where they have no roots, no sense of belonging, and no family. She is depriving them of the environment in which they have grown up and their father.

Mother: I've told you I want to move. I am doing it for the kids as well to give them peace and quiet in their daily life and take them out of the stressful city life. When we live together and can share the tasks and responsibilities of everyday life, that's one thing, but being alone with this is a lot more. It makes for long days for me living like this. If I am to handle this and fulltime work, I can do this better with the support from my partner and a much shorter commute to my workplace.

The conflict appeared insolvable: no solution would satisfy the demands of both parties. The mother felt entitled to make life changes that she considered positive for herself and not 
RUNNING HEAD: High-conflict parents in mediation: an analysis....

harmful for the children. "After all," she said, "I am young and have my life ahead of me, and I have always been the one taking most of the responsibility for the children". Although she offered the father more time with the kids during the holidays, he was in despair over the prospect of losing daily contact with them.

There were plenty of reasons why the mother desired change in this case, and she delivered them with great enthusiasm. This is an example of a situation where it is impossible to find a compromising solution that satisfies all affected parties. Rather, such situations require finding solutions that all parties can live with, even if they are not perfect.

\section{$\underline{\text { 8. External voices deadlock the dialogue }}$}

Parents who come to mediation often bring in elements from dialogues with other people. More often than not, parents have spoken to friends and family about their situation, and they refer to what they have said. Thus, external voices often interfere with the conflict. The mediation ceases to be between just the parents but becomes a battle between the representations of different perspectives and opinions. There is no possibility to modify the opinions attributed to them by others. One example is a case in which these external voices were of the grandparents'. A young mother had broken up with a partner who had a serious gambling problem. Her father followed her to the mediation. The former partner expressed confusion about who regulated the contact with his son, the mother or her father waiting outside.

T: But do you feel that the mother is working against you? Or ... is it her parents?

Father: I don't know who is, to be honest.

$T: N o$ 
RUNNING HEAD: High-conflict parents in mediation: an analysis....

Father: I don't know anything anymore...

T: No

Father: There must be a limit to how many times somebody can agree on something with me and then go back on it and say, "No, it's the other's fault [that I did not come], [its] not my fault."

In other cases, the parents relied on expert statements from child welfare services, activist organizations, the ombudsman for children, organizations such as "Two Parents", lawyers, psychologists and so on. This did not contribute to moving the dialogue forward; rather, the opposite occurred. The other would reply by citing a different expert. When this expert was a new partner, it was particularly unhelpful.

Mother: Your partner is a lawyer and a specialist in family law. I get mail from you that is clearly not written by you, and it is provoking when they are signed your name and not your partner's...I feel like this is unfair because I come here alone and without any legal help, while you kind of have a lawyer.

There were also cases where one of the parents came to mediation with a limited mandate from an external party on how to act or what to say, such as advice from a lawyer not to agree to any deal or strong recommendations from child welfare services or other advising agencies. This gave the mediator the challenge of trying to ensure that all voices and perspectives were heard without interfering with or undermining the parents' fundamental right to make their own decisions.

\section{Discussion}


RUNNING HEAD: High-conflict parents in mediation: an analysis....

In terms of identifying HCL cases, the mediators' assessments were consistent with the parents' perceived level of disagreement prior to mediation. Experienced mediators easily identified the couples who struggled during the first session. This questions the necessity to screen out different categories of divorcing couples before mediation, an idea that has often been advocated in the field of mediation (Anderson, Anderson, Palmer, Mutchler, and Baker, 2010; Ballard and Beck, 2011). Realizing that you are meeting a couple that is really striving to cope with the situation is quite different from trying to determine whether the couple belongs to one category or another. Attempting to categorize the couple may divert the mediator's attention from the couples themselves.

Furthermore, the parents in the HLC-group appeared to be very much aware of the conflicts they brought with them to mediation. The formal guidelines for mediation in Norway emphasizes the mediators' responsibility to inform the couples about laws and regulations, the value of agreements, topics relevant to discuss, normal or typical reactions in children, recommended arrangements, and so on. This kind of informative practice may work well for parents arriving for mediation with a mutual understanding of how they will arrange the future care of their children; it usually emphasizes and confirms ideas they already share. In the first meeting with HLC-cases, mediators can clearly deemphasize both the informative practice and the focus on agreement and instead engage in attentive listening to topics that nurtures the discussion of conflicts. Furthermore, we have noted effective reasons to avoid discussions based on general terms such as "the best interest of the children" and "principles of fairness". When parties in conflict deal with these concepts, arguments arise that widen the gap between them. Neither informative practice nor a strict agreement orientation appears to be advisable when one or both of the parents are deeply concerned and upset.

Finally, the present description of conflict-driving elements is an invitation to go beyond the former divisions of agreement-oriented and emotional-oriented mediation described in the 
RUNNING HEAD: High-conflict parents in mediation: an analysis....

current literature. Conflict-driving elements concern both agreements and emotions.

Accordingly, both aspects need to be addressed, partly with focus on how the parents relate to each other and partly on how this influences the daily care for their children. The three main topics we have highlighted address how the parties relate to the breakup, concerns about personal differences between them in coping with their lives and the impact on living conditions and the context surrounding the family. Each one of these topics involves emotional reactions and implications concerning the care for the children.

By being conscientious of the possible sources of conflict, the mediator can put some of the relational and emotional drivers into words, helping the parents see what might hinder them in reaching a desired agreement. This does not mean redefining mediation to therapy, where emotional and relational processes are the focus and goal. Rather, it means empowering the mediator to address what is there to make the parents conscious of it, validate it, explore it and make it understandable for them. In the next step, based on a shared and more nuanced picture of the differences and the similarities between them, the mediator can start to look for the practical implications for proper care for their children.

This is difficult to achieve within the one mandatory mediation session in the Norwegian context, especially with HLC parents. To help them from being stuck in conflicts it seems crucial that they meet for more sessions. This calls for strategies helping the mediator to slow down the process; a topic we will return to in another paper.

This study does not consider whether the parents' concerns were anchored in real events or with different experiences of reality; it is likely to involve a bit of both. Nevertheless, these concerns stood out as very real and very strong sources and drivers of conflict in the analyzed dialogues. Labeling these concerns as sources does not indicate that these are the "real" or 
RUNNING HEAD: High-conflict parents in mediation: an analysis....

underlying causes of the antagonism between the parents. There are always multiple causes and different levels of explanations.

For mediators to maintain their position in the mediation of HCL couples, they must accept the parties as they appear in the mediation context, focusing on the idea that, on some level, they have a wish to continue a common parenthood for their children. A bitter history of a breakup, deeply held concerns for their children and fears for the future may hinder this. The topics we have presented can help mediators explore such obstacles to support the parents in moving closer to an agreement. Certainly, there are cases that must go through childcare authorities or the court, but this is not a conclusion that should be drawn prematurely.

\section{Conclusion}

This study described characteristics of dialogues between parents experiencing a high level of conflict. The dialogue was dominated by rapid changes of topics, frequent interruptions, escalations of verbal and non-verbal emotional expressions, and lack of mutual validation.

We have identified eight sources of conflict underlying the disagreements regarding the specifics of shared care and living arrangements. Two of these sources were related to the breakup, four to the care for and understanding of the children, one to differences in the parents' plans for the future and one to the interference of external voices on the mediation dialogue.

Identifying such sources of conflict should help the mediator put into words and raise awareness of some of the emotional and interpersonal reactions that hinder parents from constructive discussion about the future care for their child. This is an important first step in the process of mediation. 
RUNNING HEAD: High-conflict parents in mediation: an analysis....

\section{References}

Amato, P. R. 2000. The consequences of divorce for adults and children. Journal of Marriage and the Family, 62: 1269-1287.

Anderson, S.R., Anderson, S. A., Palmer, K. L., Mutchler, M. S., and Baker, L.K. 2010.

Defining high conflict. The American Journal of Family Therapy, 39(1): 11-27. DOI: $10.1080 / 01926187.2010 .530194$.

Ballard, R. H. and Beck, C. J. A. (2011). Detecting intimate partner violence in family and divorce mediation: A randomized trial of intimate partner violence screening. Psychology, Public Policy, and Law, 17(2): 241-263.

Baitar, R., Buysse, A. Brondeel, R. de Mol, J., and Roper, P. (2012). Toward higH-quality divorce agreements: The influence of facilitative professionals. Negotiation Journal, 28(4): $453-473$.

Beck, C. J. A., and Sales, B. D. (2001). Family mediation: Facts, myths, and future prospects. Washington, DC: American Psychological Association.

Baitar, R., Buysse, A. Brondeel, R. de Mol, J., and Roper, P. (2012). Toward high-quality divorce agreements: The influence of facilitative professionals. Negotiation Journal, 28(4): $453-473$.

Brown, E. M. 1997. Comprehensive divorce mediation. In E. Kruk (ed.), Mediation and conflict resolution in social work and the human services, (pp. 37-54). Chicago: Nelson-Hall.

Bush, R. A. B. and J. P. Folger. 2005. The promise of mediation. The transformative approach to conflict. San Francisco: John Wiley \& Sons. 
RUNNING HEAD: High-conflict parents in mediation: an analysis....

Charmaz, K. 2008. Grounded theory. In J. A. Smith (red.), Qualitative psychology. A practical guide to research methods (pp. 81-110). Los Angeles: Sage Publications.

Cheng, H., J. Dunn, T. G. O'Connor, J. Golding, and the ALSPAC Study Team. 2006. Factors Moderating Children's Adjustment to Parental Separation: Findings from a Community Study in England. Journal of Abnormal Child Psychology, 34(2): 239-250.

Coogler, O. J. 1978. Structured mediation in divorce settlement: A handbook for marital mediators. Lexington, M. A.: Lexington Books.

Eddy, B. 2006. High conflict people in legal disputes. Canada: Janis Publications.

Ekeland, T.-J. 2004. Konflikt og konfliktforståelse for helse- og sosialarbeidere. (Conflict and conflict understanding for social workers). Oslo: Gyldendal Akademisk.

Emery, R. E. 1999. Marriage, divorce, and children's adjustment (2. ed.). Thousand Oaks, CA: Sage.

Emery, R. E., Laumann-Billings, L., Waldron, M. C., Sbarra, D. A., \& Dillon, P. (2001). Child custody mediation and litigation: Custody, contact, and co-parenting 12 years after initial dispute resolution. Journal of Consulting and Clinical Psychology, 69:

$323-332$.

Emery, R. E., D. Sbarra, and T. Grover. 2005. Divorce mediation: Research and reflections. Family Court Review, 43: 22-37.

Garcia, A. C. 2012. Advice-giving and disputant empowerment in divorce mediation sessions. Language and Dialogue, 2: 398-426. 
RUNNING HEAD: High-conflict parents in mediation: an analysis....

Gulbrandsen, W., and O. A. Tjersland. 2011 a, b. Foreldremekling ved samlivsbrudd.

Forskningsrapporter (Divorce mediation. Research reports). University of Oslo: Department of Psychology.

Haynes, J. M. 1981. Divorce mediation: A practical guide for therapists and counsellors. New York: Springer Publishing Company.

Heisterkamp, B. L. 2006. Conversational displays of mediator neutrality in a court-based program. Journal of Pragmatics, 38, 2051-2064.

Irving, H. H., and M. Benjamin. 2002. Therapeutic family mediation: Helping families resolve conflict. Thousand Oaks, California: Sage publications.

Jacobs, S. 2002. Maintaining neutrality in dispute mediation: managing disagreement while managing not to disagree. Journal of Pragmatics, 34: 1403-1426.

Kelly, J. B. 2000. Children's adjustment in conflicted marriage and divorce: A decade review of research. Journal of the American Academy of Child and Adolescent Psychiatry, 39: 963983.

Kressel, K., E. A. Frontera Rutgues, S. Forlenza, F. Butler, and F. Fish. 1994. The settlementorientation vs. the problem-solving style in custody mediation. Journal of Social Issues, 50: 67-84.

Lang, M. and A. Taylor. 2000. The making of a mediator: developing artistry in practice. San Francisco: Jossey-Bass.

Lov om barn og foreldre (4.th of August, 1981) (Law on Children and Parents).

Lov om ekteskap (4th. of July, 1991) (Law on Marriage). 
RUNNING HEAD: High-conflict parents in mediation: an analysis....

McIntosh, J. E., Y. D. Wells, and C. M. Long. 2007. Child focused and child inclusive family law dispute resolution. One year findings from a prospective study of outcomes. Journal of Family Studies, 13(1): 8-25.

Olekalns, M., J. Brett, and W. Donohue. 2010. Words are all I have: Linguistic cues as predictors of settlement in divorce mediation. Negotiation and Conflict Management Research, 3:145-168.

Poitras, J., and S. Raines. 2013. Expert mediators. Overcoming mediation challenges in workplace, family, and community conflicts. Lanham: Jason Aronson.

Picard, C. and Siltanen, J. 2013. Exploring the significance of emotion for mediation practice. Conflict Resolution Quarterly, 31: 31-55.

Saposnek, D. T. 1998. Mediating child disputes. A strategic approach. San Francisco: JosseyBass.

Saposnek, D. T. 2004. Commentary: The Future of the History of Family Mediation Research. Conflict Resolution Quarterly, 22: 37-53.

Sbarra, D. A. and R. E. Emery. 2006. In the presence of grief: The role of cognitive-emotional adaptation in contemporary mediation. In M. A. Fine, and J. H. Harvey (ed.), Handbook of divorce and relationship dissolution (pp. 553-602). New York: Routledge.

Shaw, L.A. (2010). Divorce mediation research: A meta-analysis. Conflict Mediation Quarterly, 27(4), 447-467.

Tjersland, O. A. 1999. Evaluation of Mediation and Parental Cooperation Based on Observations and Interviews with the Clients in a Mediation Project. Mediation Quarterly, 16: $407-423$. 
RUNNING HEAD: High-conflict parents in mediation: an analysis....

Tjersland, O. A. and W. Gulbrandsen. 2010. Mekling ved samlivsbrudd: modeller og ideologi (Divorce mediation: models and ideology). Tidsskrift for Norsk Psykologforening, 47(8): $692-700$.

Tjersland, O. A., W. Gulbrandsen, and H. Haavind. 2015. Mandatory mediation outside the court - does it works satisfactory with parents in high conflicts? Conflict Resolution Quarterly, 33(1): 19-34.

Wall, J. A., T. C. Dunne, and S. Chan-Serafin. 2011. The effects of neutral, evaluative, and pressing mediator strategies. Conflict Resolution Quarterly, 29: 127-150.

Winslade, J. and G. Monk. 2001. Narrative mediation. A new approach to conflict resolution. San Francisco: Jossey-Bass.

Ådanes, M., G. M. D. Haugen, H. Jensberg, T. Lossius Husum, and M. Rantalaiho. 2011. Evaluering av mekling etter ekteskapslov og barnelov. (An evaluation of mediation according to Norwegian Laws). Oslo: SINTEF-Rapport A20162.

\section{Authors}

Wenke Gulbrandsen, PhD, Research Fellow at the FORM-project, Department of Psychology, University of Oslo, and Community psychologist in Borough Ullern, Oslo.

Hanne Haavind, professor in clinical and developmental psychology in the Department of Psychology, University of Oslo.

Odd Arne Tjersland, professor in clinical and family psychology in the Department of Psychology, University of Oslo. 